\title{
Best-practice Language Learning Online: A State-of-the-Art Review
}

\section{Uschi Felix (Monash)}

Many metaphors have been used to describe the Internet or the World Wide Web, the most rehearsed being the Information Superhighway. This, however, immediately gives the impression that their major function is to make information highly accessible and to provide it very quickly. While this function has an important role in education, it is only one of many elements in a broad spectrum of considerations which need to be orchestrated carefully in the quest for best practice in online language learning. Bateson's (1977)* metaphor of the orchestra seems, indeed, to be much more fitting. An orchestra going through the process of learning a new piece with the ultimate goal of turning out a public performance is a useful analogy for the experience which a group of students and their teacher might share in an excellent online learning and teaching endeavour. A good conductor will facilitate and guide the enterprise, allowing players singly and in groups to shape the interpretation, and ultimately share ownership of the creation. Successful musicians will be intrinsically motivated, in tune with each other, prepared to work hard and open to new ways of reaching the desired goal, constantly updating their skills at both micro and macro levels. Their instruments will be of the best quality, finely tuned, highly reliable and supported by specialists, and the surrounding acoustics will be impeccable.

This scenario describes ideal conditions which are rarely found in educational settings, although the Virtual Wedding project (Svensson 2003) in which students build virtual worlds in a state-of-the-art laboratory comes very close. Most of us are still faced with a large number of constraints that include unmotivated students, institutional pressures, lack of time, malfunctioning technology, access problems and poor technical expertise (see Felix 2003a for a detailed discussion). The other significant

\footnotetext{
* Full bibliographical references for this article appear on pages 186-190.
} 
difference between the orchestra rehearsal and online language learning is that in the former the outcome is always largely known. The exciting promise of some online learning environments is that the outcome will be shaped by the process in which the combination of students' interests, abilities, technological and linguistic expertise, group dynamics and serendipitous experiences contributes differently and often unexpectedly to what might have been set as a common goal. The differential outcomes of the simulation globale (Shield 2003), a collaborative MOO-based project in which students create French towns and put in tenders for running summer schools, is clear proof of this assertion.

Not everyone would agree that this is a desirable situation, say in comparison with a structured task leading to mastery of something as tangible as the perfect tense. Online environments have often been seen as being chaotic, with learning apparently out of control (Vogel 2001). This may well be true in some instances where collaborative online learning has suffered a similar fate to some ill-conceived communicative learning events, in which the process consists of no more than "communicating" and the outcome of "having communicated." Goodyear (2002:70) puts this very succinctly:

Tasks designed with eyes too narrowly focused on well-specified learning outcomes may prove detrimental to the ongoing life and health of a networked learning community. Too heavy a preoccupation with the vivacity of a networked learning community may result in plenty of talk but all too little learning.

Thankfully, the recent literature shows an ever-growing number of examples of sound pedagogical practice using the Web and the Internet, both in dealing with structured tasks supporting cognitive learning approaches (Whistle 1999, Ganderton 1999, Labrie 2000, Pujolà 2001, Beaudoin 2001, Heift 2002) and open-ended, so-called "ill-structured" projects supporting social constructivist approaches (Nelson \& Oliver 1999, Barson 1999, Shield et al 2001), or both (Erben 1999, Popov 2001, Chun \& Plass 2000). The encouraging aspect of the new technologies is that they offer the potential to do both; to do either well, however, is 
enormously challenging and often time consuming and costly. The metaphor of the orchestra still holds insofar as myriad elements need to be brought together in harmony in order to meet this challenge. In an extensive review of key elements in Web-based instruction, Jung (2001) identified the following: content expandability, content adaptability, visual layout, academic interaction, collaborative interaction, interpersonal interaction and learner autonomy. To do justice to all of these elements is a great challenge, especially for teachers who design their course materials in the absence of extensive support structures.

A clear definition of what might be meant by online language learning, or best practice, is almost impossible to provide. There are as many different approaches as there are nomenclatures and learning theories (Felix 2003a), and the task is not made easier by a lack of congruity between learning theory and teaching practice (Goodyear 2002). This in itself is no different from classroom learning, but we now have to deal with the added complication of the role of technology in the process.

Generally it can be said that there are two major forms of online learning. On the one hand, there are stand-alone online courses that strive to operate as virtual classrooms, in which the technology acts both as tutor and tool. High quality examples are still very rare in languages (see Cyberitalian, Global English, Interdeutsch). On the other hand, there are add-on activities to classroom teaching or distance education courses in which technology is used primarily as a tool and a communication device. Teachers are present to varying degrees in both forms, and both range currently from poor to excellent, just as classroom teaching does not hold an automatic monopoly on best practice education. In either context, we interpret best practice to mean using the most appropriate tools to their best potential to achieve sound pedagogical processes and outcomes.

Coinciding with the newer networked technologies, there has been a move away from learning theories favouring instructivist approaches to constructivist ones, engaging students in problem solving, situated learning and co-operative activities, often crossing national and international boundaries. Interestingly this move does not reflect radically new philo- 
sophies in teaching but sees the pendulum swinging back once again to progressive methods (see Windschitl, 2002; Bain, 2003), which reflect the theories of Vygotsky (1978), Dewey (1963) and Leont'ev (1978) who emphasise interpersonal, experiential, activity-based learning. It is important, though, to point out that it would be naïve to suggest a black and white divide into strictly opposing schools of thought (Duffy \& Cunningham, 1996; Goodyear, 2002). Furthermore, constructivism itself contains several different conceptual and philosophical paradigms, with the two major schools of thought representing cognitive constructivism on the one hand, and social constructivism on the other. Perhaps the most significant, yet still fairly simplistic difference between exponents of instructivist and social constructivist approaches is that the former focus on the individual in the group, believing that cognition occurs in the head of the individual, whereas the latter emphasise the socially and culturally situated context of cognition, in which knowledge is constructed in shared endeavours (Duffy \& Cunningham, 1996). Another important distinction is the focus on the outcome of learning in the former compared to inextricably linked processes and outcomes in the latter.

Few would dispute the value of social constructivist approaches in humanistic terms. After all, addressing needs and interests of students; engaging them in authentic, real-life tasks; allowing them ownership of the curriculum, to name only the most significant elements, constitute sound pedagogical values. However, both enthusiasts and critics (Mason, 1993; Levy, 1997; Felix, 1999, 2002; Bain, 2003, and especially Windschitl 2002) have articulated challenges and concerns that cannot be ignored. The major issues that have been discussed are (1) the problems that might arise through poor group dynamics, resulting in what Kollock \& Smith (1996) have termed social dilemma; (2) the need for labourintensive authentic assessment procedures (Felix, 2003b); and (3) what seems most pertinent for language learning: the added difficulty in achieving linguistic accuracy. While it is not suggested here that these challenges are insurmountable, what has become abundantly clear to anyone involved in constructivist ventures is the fact that addressing them has major time implications (Felix 2003a). If we want to achieve the best 
results for our students, we must be prepared to invest serious time in monitoring group dynamics, devising elaborate assessment procedures that match the processes of learning in which students are engaged, and finding ways of raising linguistic accuracy without compromising a learning climate that emphasises risk-taking while allowing students to make errors in a safe environment. A tall order indeed, especially in view of the impossibility of conjuring up many extra hours in our working day.

However, why not revisit what the computer can do for us in terms of automation? Through many years of battling with time constraints, this author feels strongly about combining instructivist and constructivist approaches in online learning, because the former will free up considerable time to engage more fully in the latter. Naturally this claim only holds if we do not have to carry out all of the developments ourselves. There are numerous resources available on CD-ROM or on the Web that will engage students in many hours of work for listening and reading comprehension, and the acquisition of vocabulary and cultural knowledge (see Felix 2001). Disappointingly though, these resources tend to consist predominantly of traditional drill-and-practice paradigms with poor feedback structures. If we are serious about the value of engaging students in meaningful, contextualised activities, it would seem unnatural to disrupt the overall climate and dynamics of the enterprise by sending students off to engage with impersonal, decontextualised materials. Felix (2003c) looks at the various creative ways in which automated activities for language learning might be enriched and humanised, in particular detailing how features such as personalised hints and graphics might be instrumental in the quest for better pedagogical practice in automated online feedback.

The most important consideration in achieving best practice is the distinction between delivering static content and creating interactivity and connectivity (Felix 2002). If all we offer online are course materials and activities in the form of drill and practice, then the harsh criticisms of bad quality teaching are well deserved and we will not have advanced from the mistakes we made in the language laboratory and early CD-ROM eras. Worse still, we will be engaging in poor pedagogy with the added 
frustration of poorer functionality (see Arneil \& Holmes 2003, Bangs 2003 for more detail). If all we offer is a simulation of what might be done in a classroom, then we may be underestimating the added pedagogical potential that some of the new technologies carry with them, such as exploiting authentic information gaps, for example. With the wisdom of hindsight, though, the picture is changing and the best current approaches are driven by sound pedagogical considerations. In these the technology is being used as a tool with a variety of objectives, but two major trends can be identified. In the first the new technologies are used to create learning environments in which an imaginative teacher can set up authentic learning tasks and collaborative projects, in which both the processes and the goals are stimulating and engaging, and which take individual student differences and interests into account. This is far removed from Noble's justified criticism of the content-driven, technology-as-tutor, computer-replacing-the-teacher paradigm of online learning (Noble 2001).

The other trend is for practitioners to take advantage of the latest developments in Intelligent CALL (see the special issue, Vol. 15 (5), of $C A L L$ ) and more sophisticated handling of server-side programming. This allows for the provision of structured online learning activities and sophisticated feedback, all tailored to individual students' strengths and weaknesses. The best versions of these demonstrate the technology's role in engaging students in both cognitive and metacognitive learning processes. Systems of this type have been developed by Heift $(2001,2002)$ in the context of teaching grammar, and by Pujolà (2001) to help with reading and listening comprehension. Heift's feedback is generated by an Intelligent Language Tutoring System (ILTS). This parser-based system analyses student input and provides error specific feedback, exclusively in the target language, and includes a facility that matches feedback messages to learner expertise and provides remedial exercises. The underlying pedagogy of the programme reflects Garrett's (1987) discussion of the use of Natural Language Processing (NLP) for providing sophisticated feedback in which the individual explanation of errors mirrors more closely what might take place in a face to face setting. An interesting 
aspect of Pujolà's programme is that it also provides a delayed two-step option that allows users to reflect on the reason for an error before accessing the explanation. Both authors have run evaluations of their systems which showed that the majority of learners do in fact make use of these hint facilities. Furthermore, Heift cites a number of studies that have found metalinguistic feedback to have more positive effects than traditional forms (Nagata, 1995, 1996; Nagata \& Swisher, 1995). She also points to research by Van der Linden (1993) which showed that lengthy feedback messages are not being attended to and that feedback dealing with multiple errors was found to be too complex. Virvou, Maras \& Tsiriga (2000:13), who developed a similar programme to Heift's for teaching the passive voice of English grammar, found that the "Passive Voice Tutor was successful in achieving a high degree of compatibility with the human experts' opinion."

Using a similar Intelligent CALL system, Chen \& Tokuda (2003), Chen, Tokuda \& Xiao (2002) and Tokuda \& Chen (2001) have developed a sophisticated programme for online translation training based on template pattern matching. The templates use words or phrases as a minimal unit, with the databases selected by experienced language teachers in the light of responses collected from sample students. The programme includes a heaviest common sequence algorithm for matches aimed at identifying, from among a large number of possible paths embedded within the template, the path with the greatest similarity to the learners' input translation. What the programme delivers is error contingent feedback for each student input.

While less sophisticated in terms of ICALL, an interesting approach to providing personalised feedback comes in Arana's Spanish Language Exercises which provide explanatory comments on correct answers as well as erroneous ones. Reinforcing success in this way seems a psychologically sound approach to the material. It is motivating, and it is an excellent way of increasing the illusion of personal contact. Not that comments do not sometimes irritate. Jovial responses to correct answers whether the same one every time or one selected at random from a small list - can grate. Elaborate sound effects tend to be the most irritating 
versions in programmes where students will hear the same sound repeatedly at every right or wrong turn. Neutral responses (Yes/Right or No/Sorry) look safer here, even if they are not "interesting." The problem in creating something more imaginative is striking the right tone for the audience. Testing various options with the target group is imperative here. Alternatively, graphics offer attractive options.

Naturally, the approaches described above contain elements of the technology-as-tutor paradigm. That the teacher will be replaced by these learning endeavours, however, is a ludicrous assumption, especially when we consider the crucial role the teacher continues to play in developing, monitoring and evaluating these sorts of activities (see Hémard 2003). If anything emerges clearly from the recent literature, it is that using technology in quality learning environments actually increases the need for teacher time and commitment (Nelson \& Oliver 1999, Brabazon 2001, Morgan 2001, Rocklin 2001).

The difficulty of catering for the development of oral production skills has long been deplored in distance language teaching (Abrioux 1991, Williams \& Sharma 1988), and not much has changed since these observations were made. Oral activities are still conspicuously absent from online offerings, and students' complaints about this usually head the list of disadvantages associated with Web-based language learning (Felix 2001). However, during the last few years practitioners have begun to incorporate sophisticated applications in the form of synchronous audiographics (Lyceum), voiced bulletin boards and email (Wimba) and voiced chats (Traveler).

These are very challenging environments, of course. While they offer learners the possibility of anonymity and the opportunity to make mistakes in an unthreatening and entertaining environment, they pose several serious problems that need to be addressed by teachers before embarking on activities. First of all, there is the claim that synchronous communications can restrict students (Berge 1999). This is especially true with learners of another language at lower levels of proficiency. While the environment in Lyceum and Traveler may well offer anonymity, it 
does not allow for the luxury of careful composing, reflection and multiple re-recording of the asynchronous Wimba bulletin board and email facility. Rather than throwing students into such an environment at the deep end, a clear need for its use has to be established. The advantage that Traveler offers over Wimba is that it provides authenticity both of task and setting. While the latter, like Lyceum, lends itself well to structured learning activities, the former offers opportunities for risktaking and unplanned communication with native speakers under real-life speaking conditions, dealing with authentic information gaps.

The price to pay for this authenticity, however, can sometimes be inappropriate and unwanted communications generated by dubious anonymous characters, seriously compromising Kollock \& Smith's (1996) proviso of a clearly defined group boundary in successful management of collective resources. While adults may cope with such intrusions easily enough, in school environments negotiation of a private channel may be advisable. This will reduce authenticity but allow for well planned, small group interaction around a set task, say a debate or a short play, to which native speakers might be invited as contributors, monitors or arbitrators. An idea for using both applications for different purposes would be to produce an interactive story or play on Wimba and then act it out in Traveler. A wonderful feature of all three environments is that they allow students to choose between anonymity and public exposure, and to move freely between real and imaginary worlds, which not only caters for different learning styles and preferences but also offers real opportunities for reducing language anxiety.

...[P]articipants in synthetic environments often feel as if the machine-based agents they encounter are real human beings, an illustration of the general principle that users tend to anthropomorphize information technologies (Weitzenbaum 1976). As a complement to responding to knowbots as if they were human, participants in a virtual world interacting via avatars tend to treat each other as imaginary beings. (Dede 1996:26) 
If we look at what unites authors who publish on CALL and ICT in Education, it is with rare exceptions a palpable enthusiasm for the subject. These authors have a great deal of experience on which to draw but this also imbues their work with an equal measure of caution. There is a strong consensus on the importance of training and technical literacy and the need to use technology appropriately and not simply because it is available. There is no claim that online learning will ever replace face-toface learning, nor a suggestion that learning a language entirely online could ever be seen as ideal. What the literature demonstrates, however, is that the new technologies offer potential for authentic encounters and constructivist learning well beyond even the best classroom simulations; that automated exercise and feedback routines do not have to be confined to drill-and-practice models but can be individualised and meaningful; and that if we are forced to teach fully by distance, these ventures no longer need to represent impoverished versions of live classes but can engender a strong sense of community. To achieve this we need to understand what elements constitute good design both in technical and pedagogical terms, to invest seriously in providing the best feedback possible, and to have the courage to take the risks associated with letting go of traditional learner/teacher relationships.

In terms of predicting the future of online learning, this author is with Groucho Marx who claimed that the past was much easier to be certain about than the future. However, if we take into account developments over the last half decade, we can identify several trends that look as if they might gain momentum. First, there is some indication that duplication of efforts is decreasing. The availability of collections of excellent resources such as the American Association of German Teachers' site is leading many teachers to integrate existing materials rather than create their own. It is hoped that world-wide repositories of reusable or tradeable learning objects (see Felix 2003a for more detail) will lead to more use of shared materials. Secondly, if we can be confident that automated online exercise routines are becoming more intelligent and pedagogically sound, we will be able to free up time to engage students in more extensive experiential activities. Thirdly, there has been much 
greater use of the new technologies for authentic encounters with the target language and culture. The trend towards task-based learning, engaging students in Web quests and problem solving activities, and collaborative project-based ventures using synchronous and asynchronous text-based and graphical environments is perhaps gaining the greatest momentum. It is most likely that there will be increased communication between native and non-native speakers, whether for rehearsal purposes or as the only medium in which communication in the target language is likely to occur-depending of course on how we view this third space that we inhabit online. Fourthly, even though the possibility of engaging students in good quality oral activities online has only just offered itself, it is impossible to imagine that this will not become a standard feature of excellent online offerings, especially in distance education. The versatility of applications like Wimba which has just added a synchronous platform to the asynchronous voice board and voice mail, and the voiced tutorial Lyceum, together with increased ease of use of such products, will transform the experience of students learning a language at a distance. Lastly, and perhaps most importantly, the call for rigorous research into outcomes is becoming more urgent. We have invested enormous resources in terms of money, time and stress in languages in order to produce impressive learning materials online. While a small body of research (see Felix 2001) and our instincts lead us to believe that this investment is worthwhile, we need more large-scale studies to reassure ourselves and relevant funding bodies that real learning outcomes are being achieved. The search for appropriate research paradigms (Chapelle 1997) will continue as the technologies provide ever more sophisticated arenas for language learning. 


\section{References (German Online)}

Abrioux, D. (1991). "Computer-Assisted Language Learning at a Distance: An International Survey." American Journal of Distance Education 5 (1), 3-14.

Arneil, S., \& Holmes, M (2003). "Servers, Clients, Testing and Teaching." In: U. Felix (ed.), Language learning online: Towards best practice. Lisse: Swets \& Zeitlinger, 147-171.

Bain, J. (2003). "Slowing the Pendulum: Should We Preserve some Aspects of Instructivism?" Paper delivered at the World Ed-Media Conference, Hawaii.

Bangs, P. (2003). "Engaging the Learner - How to Author for Best Feedback." In: U. Felix (ed.), Language learning online: Towards Best Practice. Lisse: Swets \& Zeitlinger, 147-171.

Barson, J. (1999). "Dealing with Double Evolution: Action-Based Learning Approaches and Instrumental Technology." In: R. Debski \& M. Levy (eds.), WORLDCALL: Global Perspectives on Computer-Assisted Language Learning. Lisse: Swets \& Zeitlinger, 11-32.

Bateson, G. (1977). Vers une écologie de l'esprit. Paris: Seuil.

Beaudoin, M. (2001): "Le Devoir conjugal: de la conceptualisation à la diffusion." ALSIC 4 (1), 91-102.

Berge, Z. (1999). "Interaction in Post-Secondary Web-Based Learning." http://www.saskschools.ca/ parkland/interaction.htm

Brabazon, T (2001). "Internet Teaching and the Administration of Knowledge." http:/www.firstmonday.org/issues/issue6 6/brabazon/index.html

Chapelle, C. (1997). "Call in the Year 2000: Still in Search of Research Paradigms?" Language Learning \& Technology 1 (1), 19-43.

Chen, L., Tokuda, N., \& Xiao, D. (2002). "A POST Parser-Based Learner Model for Template-Based ICALL for Japanese-English Writing Skills." Computer Assisted Language Learning 15 (4), 357-372.

Chen, L. \& Tokuda, N. (2003). "Bug Diagnosis by String Matching: Application to ILTS for Translation." CALICO 20 (2), 227-244.

Chun, D.M. \& Plass, J. L. (2000). "Networked Multimedia Environments for Second Language Acqusition." In: M. Warschauer \& R. Kern, (eds.), Network-based Language Teaching: Concepts and Practice. Cambridge: Cambridge University Press, 151-170.

Dede, C. (1996). "The Evolution of Distance Education Emerging Technologies and Distributed Learning." The American Journal of Distance Education 10 (2), 4-36.

Dewey, J. (1963). Experience and Education. New York: Collier Books. 
Duffy, T.M. \& Cunningham, D.J. (1996). "Constructivism: Implications for the Design and Delivery of Instruction." In: D. Jonassen (ed.), Handbook of Instructional Technology. New York: Simon \& Schuster Macmillan.

Erben, T. (1999). "Constructing Learning in a Virtual Immerson Bath: LOTE Teacher Education Through Audiographics." In: R. Debski \& M. Levy (eds.), WORLDCALL: Global Perspectives on Computer-Assisted Language Learning. Lisse: Swets \& Zeitlinger, 229-248.

Felix, U. (1989). An Investigation of the Effects of Music, Relaxation and Suggestion in Second Language Acquisition in Schools. Unpublished $\mathrm{PhD}$ thesis, Flinders University, Adelaide, Australia.

Felix, U. (1999). "Web-Based Language Learning: A Window to the Authentic World." In: R. Debski \& M. Levy (eds.), WORLDCALL: Global Perspectives on Computer-Assisted Language Learning. Lisse: Swets \& Zeitlinger, 85-98.

Felix, U. (2001). Beyond Babel: Language Learning Online. Melbourne: Language Australia Ltd.

Felix, U. (2002). "The Web as a Vehicle for Constructivist Approaches in Language Teaching." ReCALL 14 (1), 2-15.

Felix, U. (2003a). "Language Learning Online: Deconstructing the Myths." Australian Journal of Educational Technology 19 (1), 118-138.

Felix, U. (2003b). "Pedagogy on the Line: Identifying and Closing the Missing Links." In: U. Felix (ed.), Language Learning Online: Towards Best Practice. Lisse: Swets \& Zeitlinger, 147-171.

Felix, U. (2003c). "Humanizing Automated Online Learning Through Intelligent Feedback." ASCILITE Conference, the University of Adelaide, Proceedings, 178-187.

Ganderton, R. (1999). "Interactivity in L2 Web-Based Reading." In: R. Debski \& M. Levy (eds.), WORLDCALL: Global Perspectives on Computer-Assisted Language Learning. Lisse: Swets \& Zeitlinger, 49-66.

Garrett, P. B. (1987). "A Psycholinguistic Perspective on Grammar and CALL." In: W. F. Smith (ed.), Modern Media in Foreign Language Education: Theory and Implementation. Lincolnwood: National Textbook, 169-196.

Goodyear, P. (2002). "Psychological Foundations for Networked Learning." In: C. Steeples, \& C. Jones (eds.), Networked Learning: Perspectives and Issues. London: Springer, 4975 .

Heift, T. (2001). "Error-Specific and Individualised Feedback in a Web-Based Language Tutoring System: Do they Read it?" ReCall 13 (1), 99-109.

Heift, T. (2002). "Learner Control and Error Correction in ICALL: Browsers, Peekers and Adamants." CALICO 19 (3), 295-313. 
Hémard, D. (2003). "Language Learning Online: Designing Towards User Acceptability." In: U. Felix (ed.), Language Learning Online: Towards Best Practice. Lisse: Swets \& Zeitlinger, 147-171.

Jung, I. (2001). "Building a Theoretical Framework of Web-Based Instruction in the Context of Distance Education." British Journal of Educational Technology 32 (5), 525-534.

Kollock, P. \& Smith, M. (1996). "Managing the Virtual Commons: Cooperation and Conflict in Computer Communities." In: S. Herring (ed.), Computer Mediated Communication: Linguistic, Social, and Cross Cultural Perspectives. Amsterdam: John Benjamins, 109-128.

Labrie, G. (2000). "A French Vocabulary Tutor for the Web." CALICO 17 (3), 475-499.

Leont'ev, A. N. (1978). Activity, Consciousness, and Personality. M.J. Hall, trans. Englewood Cliffs, NJ: Prentice Hall.

Levy, M. (1997). "Project-Based Learning for Language Teachers: Reflecting on the Process." In: R. Debski, J. Gassin \& M. Smith (eds.), Language Learning Through Social Computing. Occasional Papers 16. Melbourne: ALAA and the Horwood Language Centre, 181-199.

Mason, R. (1993). "Designing Collaborative Work for Online Courses.” In: G. Davies \& B. Samways (eds.), Teleteaching. Proceedings of the IFIP TC3 Conference, TeleTeaching 93, Trondheim, Norway, 569-578.

Morgan; C. (2001). "Seeking Perseverance Through Closer Relations with Remote Students." Conference Proceedings (short papers), ASCILITE'01: Meeting at the Crossroads, Melbourne, Victoria, 125-128.

Nagata, N. (1995). "An Effective Application of Natural Language Processing in Second Language Instruction." CALICO 13 (1), 47-67.

Nagata, N. (1996). "Computer vs. Workbook Instruction in Second Language Acquisition." CALICO 14 (1), 53-75.

Nagata, N. \& Swisher M. V. (1995). "A Study Of Consciousness-Raising by Computer: The Effect of Metalinguistic Feedback on Second Language Learning." Foreign Language Annals 28 (3), 337-347.

Nelson, T. \& Oliver, W. (1999). "Murder on the Internet." CALICO 17 (1), 101-114.

Noble (2001). Personal interview on ABC Radio National broadcast. http://abc.net.au/m/talks/bbing/mod/bbing 20012002 2856.ram

Popov, C. (2001). "InterDeutsch-Going solo: First steps into Virtual Teaching on a Zero Budget." In: U. Felix, (ed.), Beyond Babel: Language Learning Online. Melbourne: Language Australia, 15-28. 
Pujolà, J-T. (2001). "Did CALL Feedback Feed Back? Researching Learners' Use of Feedback." ReCall 13 (1), 79-99.

Rocklin, T. (2001). Do I Dare? Is it Prudent? National Teaching and Learning Forum Newsletter 10 (3); Oryx Press.

Shield, L., Weininger, M.J. \& Davies, L.B. (2001). "A Task-Based Approach to Using MOO for Collaborative Language Learning." In: K. Cameron (ed.), CALL and the Learning Community. Exeter: Elm Bank Publications, 391-401.

Shield, L. (2003). "MOO as a Language Learning Tool." In: U. Felix (ed.), Language Learning Online: Towards Best Practice. 147-171. Lisse: Swets \& Zeitlinger.

Svensson, P. (2003). "Virtual Worlds as Arenas for Language Learning." In: U. Felix (ed.), Language Learning Online: Towards Best Practice. Lisse: Swets \& Zeitlinger, 147-171.

Tokuda, N. \& Chen, L. (2001). "An Online Tutoring System for Language Translation." IEEE Multimedia 8 (3) 46-55.

Van der Linden, E. (1993). "Does Feedback Enhance Computer-Assisted Language Learning." Computers \& Education 21 (1-2), 61-65.

Virvou, M., Maras, D. \& Tsiriga, V. (2000). "Student Modelling in an Intelligent Tutoring System for the Passive Voice of English Language." Educational Technology \& Society $3(4), 1-16$.

Vygotsky, L.S. (1978). Mind in Society. Cambridge, MA: Harvard University Press.

Windschitl, M. (2002). "Framing Constructivism in Practice as the Negotiation of Dile mmas: An Analysis of the Conceptual, Pedagogical, Cultural, and Political Challenges Facing Teachers." Review of Educational Research 72 (2), 131-175.

Vogel, T. (2001). "Learning out of Control: Some Thoughts on the World Wide Web in Learning and Teaching Foreign Languages." In: A. Chambers \& G. Davies, (eds.), ICT and Language Learning: A European Perspective. Lisse: Swets \& Zeitlinger, 133-145.

Weitzenbaum, J. (1976). Computer Power and Human Reason. San Francisco: W.H. Freeman.

Whistle, J. (1999). "Concordancing with Students Using an 'Off-the-Web' Corpus." ReCall 11 (2), 74-80.

Williams, S. \& Sharma, P. (1988). "Language Acquisition by Distance Education: An Australian Survey." Distance Education 9, 127-146.

\section{Websites:}

American Association of Teachers of German (AATG) http://grow.aatg.org/index.html

Cyberitalian http://www.cyberitalian.com/ 
Global English http://www.globalenglish.com/

Interdeutsch http://www.interdeutsch.de/

Lyceum http://www.open.ac.uk

Traveler http://www. digitalspace.com/traveler/

Spanish Language Exercises http://mid.ursinus.edw/jarana/Ejercicios/

Wimba http://www.wimba.com/

All websites cited in this paper were verified on 14.03.2000. 